\title{
DESCRIÇÃO DE CINCO ESPECIES NOVAS DE PSYLLOBORA CHEVROLAT, 1837 (COLEOPTERA, COCCINELLIDAE, PSYLLOBORINI)
}

\author{
Lúcia Massutti de Almeida ${ }^{1}$
}

\begin{abstract}
Five new species of the Genus Psyllobora Chevrolat, 1837 are described and illustrated: P. amazonensis, P. balinti, P. jalapaiensis, P. sicardi and P. veraecrucis.

\section{Psyllobora amazonensis sp. $\mathrm{n}$.}

(Figs. 1-4)

Diagnose: Cabeça com clípeo fundido à fronte sem depressão ou linha de sutura. Mand f́bulas robustas com bordo externo em ângulo e mola com dente. Corpo ovalar, glabro com tegumento amarelado leitoso. Pronoto sem máculas aparentes. Élitro com 6 máculas (Fig. 1): trés parcialmente unidas formando uma grande mácula que se inicia na base do élitro e se prolonga até o ápice. Esta mácula corre paralela à sutura elitral, da base até pouco antes do ápice, abrange lateralmente o calo umeral e deixa no centro do élitro um espaço mais ou menos triangular. As três outras máculas acompanham a margem externa do élitro: a mais basal pouco abaixo da altura do calo umeral, mais alongada que as demais e pouco mais alargada no centro; a intermediária alongada, e a apical não ultrapassando a mácula maior formada pela união das três primeiras máculas elitrais.
\end{abstract}

Genitália. Machos: Lobo médio largo na base, estreitando-se gradativamente para o ápice onde termina arredondado; parâmeros mais longos que o lobo médio, com cerdas longas (Fig. 2); sifão simples, sem processos laterais ou apicais (Fig. 3).

Fêmeas: Espermateca ramificada, na extremidade de sua curvatura subigual ao 1 ? estemo abdominal visível, infundíbulo cônico (Fig. 4).

Medidas: 3,58-3,67 $\mathrm{mm}$ de comprimento; $2,92-3,00 \mathrm{~mm}$ de largura.

Variaçōes: O pronoto pode apresentar uma área central ovalar mais escura que o tegumento.

Comentários: Esta espécie é próxima de P. divisa e desta difere por apresentar as máculas da $1^{\mathrm{a}}$. metade elitral unidas com as da $2^{\mathrm{a}}$. metade; por não possuir máculas no pronoto; pelo ápice do lobo médio que em $P$. divisa tem forma de seta e é mais longo; e pelo comprimento dos parâmetros que naquela espécie é subigual ao lobo médio.

1. Contribuição n? 682 do Departamento de Zoologia da UFPR

2. Pós-Graduação, doutorado, Depto. Zoologia, UFPR, Caixa Postal 19.020, 81.504, Curitiba, Paraná, Brasil. 
Revta bras. Zool.
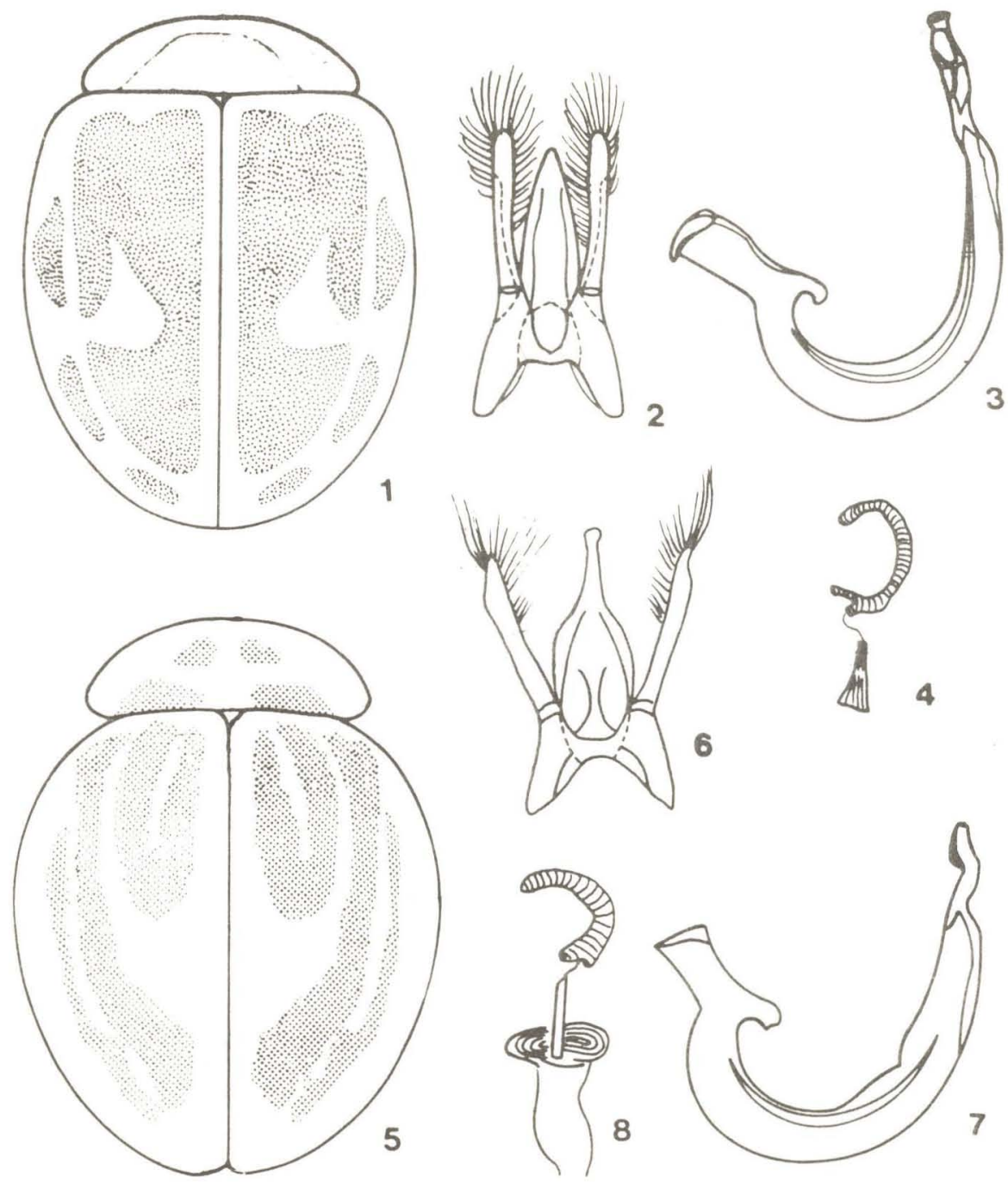

Figs. 1-8. Psyllobora amazonensis sp.n. 1. pronoto e élitros; 2. lobo médio; 3. sifão; 4. espermateca; Psyllobora balinti sp.n. 5. pronoto e élitros; 6. lobo médio; 7. sifão; 8. espermateca. 
Material Tipo: Holótipo macho, de Parintins, Amazonas, Brasil, I.1940, coletado por Balint, lâmina no 981/FCC-1383; parátipo fêmea, de mesma data e localidade do holötipo, lâmina no 980/FCC-1382. Os tipos estão depositados no Museu Nacional do Rio de Janeiro (MNRJ).

\section{Psyllobora balinti sp.n.}

(Figs. 5-8)

Diagnose: Cabeça com clípeo fundido à fronte sem depressão ou linha de sutura. Mandíbulas com bordo externo curvo, mola com dente. Corpo ovalar glabro com tegumento amarelado leitoso e máculas marrons. Pronoto com 4 máculas: um par menor triangular apical e um par maior trapezoidal basal. Élitro com 4 máculas alongadas (Fig. 5): duas máculas unidas pelo ápice que se prolongam até pouco antes da metade do élitro; uma 3a mácula paralela às duas anteriores se prolonga desde o calo umeral até quase o ápice do élitro acompanhando a curvatura do bordo elitral. A 4a mácula também muito alongada, mais estreita e paralela à anterior, iniciando-se logo abaixo da altura do calo umeral e terminando pouco antes do ápice do élitro, junto ao final da 3a mácula.

Genitália. Machos: Lobo médio largo na base, estreitando-se bruscamente a partir do meio, formando uma projeção afilada com ponta mamiliforme; parâmeros mais curtos que o lobo médio, com cerdas longas (Fig. 6). Sifāo com ápice tortuoso (Fig. 7).

Fêmeas: Espermateca ramificada, na extremidade de sua curvatura menor que o 1 . esterno abdominal visível, infundíbulo cilíndrico (Fig. 8).

Medidas: 4,84-5,07 mm de comprimento e 3,69-3,84 mm de largura.

Comentários: Esta espécie é próxima de $P$. foliäcea e dela difere por não apresentar mácula que se extende até o bordo externo do élitro; pelas duas primeiras máculas estarem separadas na base; pela 4 a mácula formar uma faixa única paralela ao bordo externo; pela forma do ápice do lobo médio; e pelo comprimento dos parâmetros que em $P$. foliacea é subigual ao lobo médio.

Material Tipo: Holótipo macho de óbidos. Pará, Brasil, X/1939, coletado por Balint, lâmina no 936/FCC-1325; parátipo de Fazenda Ricardo Franco, Norte de Cuiabá, Mato Grosso, Brasil, de 11/II/1961, coletado por J. \& B. Bechyné. Ambos estão depositados no Museu Nacional do Rio de Janeiro (MNRJ).

\section{Psyllobora jalapaiensis sp.n.}

(Figs. 9-11)

Diagnose: Cabeça com clípeo fundido à fronte sem depressão ou linha de sutura. Mandíbulas com bordo externo em ângulo, mola com dente. Corpo ovalado glabro com tegumento amarelado leitoso e máculas marrons. Pronoto com 4 máculas marrons: 2 arredondadas menores, mais unidas entre si no ápice e 2 basais, maiores de cada lado na base e mais escuras. Élitro com 8 máculas: a $1^{\mathrm{a}}$ e a $22^{\mathrm{a}}$ unidas no ápice, a $3{ }^{\mathrm{a}}$ mácula inteira iniciando no calo umeral, unida a $6^{\mathrm{a}}$ que por sua vez se une à 5 a formando assim uma longa faixa longitudinal no centro do élitro, a qual acompanha a curvatura do bordo externo; 4 ? mácula inteira, entre a 3 ?a e margem externa do élitro. 7 a mácula inteira, alongada, acompanhando a linha da 4 a , paralela ao bordo externo. 8 a mácula também alongada, no ápice do élitro (Fig. 9). 


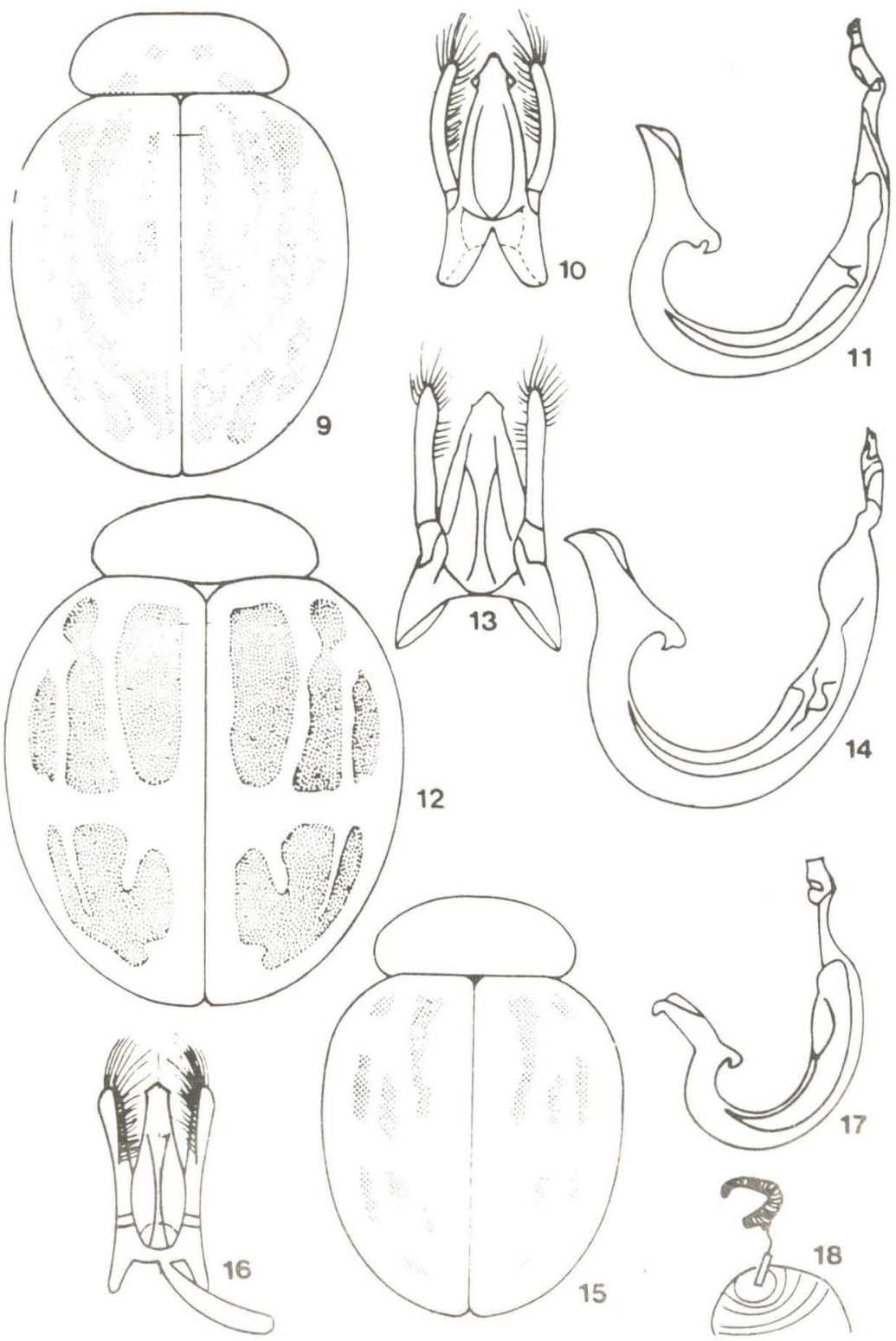

Figs. 9-18. Psyllobora jalapaiensis sp.n. 9. pronoto e élitros; 10. lobo médio; 11. sifâo: Psylloborz sicardi sp.n.; 12. pronoto e élitros; 13. lobo médio; 14. sifāo Psyllobora veraecrucis sp.n.; 15. pronoto e élitros; 16 . lobo médio; 17. sifäo; 18. espermateca. 
Genitália. Machos: Lobo médio largo na base, se estreitando para o ápice onde toma a forma de seta larga. Parâmeros estreitos, pouco menores que o lobo médio com cerdas longas (Fig. 10). Sifão sem projeções (Fig. 11).

Fêmeas: Os dois exemplares examinados não continham espermateca.

Medidas: 3,15-3,65 mm de comprimento; 2,75-2,94 $\mathrm{mm}$ de largura.

Comentários: Espécie próxima de $P$. foliacea e de $P$. balinti e delas difere por possuir as máculas elitrais mais alongadas e afiladas; pela forma do ápice do lobo médio que nas duas espécies são mais afiladas e nesta é muito mais largo e em forma de seta.

Material Tipo: Holótipo de Jalapa, México, coletado por J.T. Mason, lâmina no 495/ FCC-605; parátipos da Costa Rica, Turrialba, Schild \& Burgdorf, 1 ex., lâmina no 503/ FCC. 13 ; S. José (Nevermann), 1 ex. Os tipos estão depositados no Museu Nacional do Rio de Janeiro (MNRJ).

\section{Psyllobora sicardi sp.n.}

(Figs. 12-14)

Diagnose: Cabeça com clípeo fundido à fronte sem depressão ou linha de sutura. Mandíbulas com bordo externo curvo, mola com dente. Corpo arredondado, glabro com tegumento amarelado leitoso com máculas marrons. Pronoto sem máculas apenas mais escurecido. Élitro com 8 máculas marrons(Fig. 12): a 1 a e a 2a totalmente unidas; a $3^{a}$ inteira, com forte constrição logo abaixo do calo umeral, a $4^{\mathrm{a}}$ alongada entre a $3^{\mathrm{a}}$ e o bordo externo do élitro; $5^{\mathrm{a}}, 6^{\mathrm{a}}, 7^{\mathrm{a}}$ e $8^{\mathrm{a}}$. unidas formando uma figura irregular com aspecto de fotha trilobada.

Genitália. Machos: Lobo médio muito longo na base, estreitando-se para o ápice, este em forma de seta larga; parâmeros pouco maiores que o lobo médio com cerdas longas (Fig. 13). Sifão sem projeções (Fig. 14).

Fêmea: Desconhecida.

Medidas: 3,92 mm de comprimento; 3,25 mm de largura.

Comentáriơs: Espécie próxima de $P$. plaumanni e $P$. camargoi Difere delas pela disposição das máculas apicais que são mais unidas; pelo ápice do lobo médio que é em seta bem mais larga, de comprimento menor e mais largo na base.

Material Tipo: Holótipo de Terranova, Bahia, Brasil, V-1885, coletado por E. Gounelle (Col. Sicard) depositado no Museum National d'Histoire Natural de Paris (França) (MNHN).

\section{Psyllobora veraecrucis sp.n.}

(Figs. 15-18)

Diagnose: Cabeça com clípeo fundido à fronte sem depressão ou linha de sutura. Mandíbulas com bordo externo curvo, mola com dente. Corpo ovalado, glabro com tegumento amarelado leitoso. Pronoto mais escurecido sem máculas. Élitro com máculas negras alongadas (Fig. 15): a $1^{\text {a }}$ a mais longa, no ângulo escutelar, extendendo-se desde pouco depois da base, até quase a metade do élitro; $2^{\mathrm{a}}$ mácula pequena, sobre o calo umeral; 
3. mácula na mesma linha da 2 ? , com comprimento igual à metade da 1 a mácula, entre aquela e a 4 , esta aproximadamente de mesmo tamanho da 3 a , entre aquela e bordo externo; 5? mácula na mesma linha da 2 a e 3 ?a , pouco mais larga que as demais; 6 a mácula entre a 5 a e o bordo externo; 7 a mácula, a menor, próxima da sutura; 8 a mácula apical.

Genitália. Machos: Lobo médio mais largo na base, estreitando-se para o ápice onde se alarga e toma o aspecto de seta; parâmeros subiguais ao lobo médio com cerdas longas (Fig. 16). Sifão sem projeções (Fig. 17).

Fêmeas: Espermateca ramificada, nas extremidades de sua curvatura menor que o 1. esterno abdominal visivel, infundíbulo cilíndrico (Fig. 18).

Medidas: 2,92-3,58 mm de comprimento; 2,33-2,50 mm de largura.

Variaçōes: Esta espécie é próxima de $P$. evanescens por possuir as máculas dos élitros mal desenhadas e genitália do macho semelhante, porém dela difere por apresentar tamanho menor, máculas mais separadas entre si; a mácula do ângulo escutelar ausente; a mácula mais apical próximo da sutura é oblíqua; e ápice do lobo médio em seta mais larga.

Material Tipo: Holótipo de Veracruz, México; parátipos 8 exemplares com a mesma tocalidade do holótipo; 2 exemplares de Xalapa. Todos os tipos estão depositados no Museu Nacional do Rio de Janeiro (MNRJ) com exceção de 1 exemplar de Xalapa no Departamento de Zoologia da Universidade Federal do Paraná.

\section{REFERENCIAS}

ALMEIDA, L.M. \& MARINONI, R.C. 1983. Contribuição do conhecimento do Gênero Psyllobora Chevrolat, 1837. (Coleoptera-Coccinellidae). Revta. Bras. Ent., 27(2):165-175.

ALMEIDA, L.M., 1987. Estudo de 17 espécies do gênero Psyllobora Chevrolat, 1837 (ColeopteraCoccinellidae). Acta. Biol. Par. 14(1,2,3,4): 47-102.

BLACKWELDER, R.E. 1945. Checklist of the coleopterous insects of Mexico, Central America. the West Indies, and South America. Bull. U.S. Natn. Mus. 185(3): 343-550.

BLACKWELDER, R.E. 1957. Idem, ibidem, 185(6):V-VII, 927-1492.

CHEVROLAT, L.A.A. 1847. In d'Orbigny, Dict. Univ. Hist. Nat. 10:606.

KORSCHEFSKY, R. 1932. Coleopterorum Catalogus. XVI (120), Coccinellidae II:565-570. W. Junk. Berlin.

LIMA, A.C. 1937. Espécies de Psyllobora. (Col. Coccinellidae). Mem. Inst. Oswaldo Cruz. 32: 1-12. 2 figs. 3. est.

MULSANT, E. 1850. Species des Coléoptéres Triméres Sécuripalpes. Lyon. 1-1104.

MULSANT, E. 1866-67. Monographie des Coccinellides. M. Savy. Lyon. 1-290. (Mém. L'Acad. Imp. Lyon. 16, 1866-67). 